\title{
Prevalence of Raynaud's phenomenon in a healthy Greek population
} Paraskevi V Voulgari, Yannis Alamanos, Damiani Papazisi, Konstantinos Christou,
Christina Papanikolaou, Alexandros A Drosos

\begin{abstract}
Objective-Raynaud's phenomenon (RP) is comprised of repeated episodes of colour changes of the skin of digits on cold exposure or emotional stress. The prevalence of $\mathrm{RP}$ in the general population is variable fluctuating between $4 \%-15 \%$, among surveys. The aim of this study was to estimate the prevalence of $R P$ in a healthy working Greek population and to investigate the possible association of RP with various demographic, social and other factors.
\end{abstract}

Methods-A total of 756 employees of the University Hospital of Ioannina was included in the study. They belong to the administrative (120 subjects), nursing and technical (a representative sample of 418 and 218 subjects, respectively) personnel. Five hundred subjects (111 men and 389 women) responded in a face to face interview based on a specially conformed questionnaire. The study began in November 1997 and was completed in March 1998.

Results-Twenty six subjects with RP (1 man and 25 women) were found. Their mean (SD) age was $32.73(5.77)$ years. The prevalence of RP was $5.2 \%(0.9 \%$ in men and $6.4 \%$ in women). The sex ratio, male/female, was 1/7.1. An association between RP and migraine was found. However, there were no significant correlations of RP with smoking, alcohol and coffee consumption, dietary habits, occupational history and drug exposure. No social or other demographic parameters associated to RP frequency were found. Conclusions-The prevalence of RP $(5.2 \%)$ in the population studied is relatively low compared with previous studies. RP focuses on the fourth decade of life and affects mainly women. There was no evidence of any correlation of RP with social, environmental or personal parameters while an association of RP with migraine was found. Geographical or genetic factors, or both, may be responsible for these results.

(Ann Rheum Dis 2000;59:206-210)

Department of

Hygiene, Medical

School, University of

Ioannina

Y Alamanos

Correspondence to: Dr Drosos

Accepted for publication 1 December 1999 both, followed by a hyperaemic phase. It may be accompanied by subjective symptoms such as numbness, paresthesias and pain in the fin-
Raynaud's phenomenon (RP) is a pathological vasomotor reaction of the digital vasculature to cold exposure or emotional stress. ${ }^{1} \mathrm{RP}$ appears as attacks of blanching or cyanosis of fingers, gers involved. The colour changes are attributable to closure of the muscular digital arteries, precapillary arterioles and arteriovenous shunts of the skin causing skin pallor, followed by cyanosis. Reversal of the vasospastic period generally occurs 10-15 minutes after the stimulus (for example, low temperature) has ended; the digits then may have a blushed appearance. ${ }^{2}$ Because of the difficulty to distinguish RP from the normal physiological response to cold temperatures, the UK Scleroderma Study Group ${ }^{3}$ suggests the following terms for the diagnosis of RP: (1) definite RP is comprised of repeated episodes of biphasic colour changes on cold exposure; (2) possible $\mathrm{RP}$ is comprised of uniphasic colour changes plus numbness or paresthesia; and (3) no RP is marked by no colour changes on cold exposure.

$\mathrm{RP}$ is classified into primary or idiopathic or Raynaud's disease without underlying disease and secondary when it is related with various medical problems (for example, connective tissue diseases, drugs and toxins, occupational disorders, structural-arterial disease, haematological diseases, etc). ${ }^{24}$

The study of epidemiological characteristics of RP is interesting because of the opportunity to define RP among apparently healthy people to estimate the frequency and to determine probable associated factors. On the other hand, early diagnosis and follow up of the affected subjects may contribute to better understanding of the natural history of serious disorders (for example, scleroderma) that may develop. The prevalence of RP in the general population is unknown but it is considered to be more common in women, younger age groups and among family members of subjects with RP. ${ }^{5}$ Recent studies aiming to determine RP prevalence showed variable data depending on the diagnostic criteria, the survey technique (sampling design, interview and examination procedures) and the characteristics of the studied population in various geographical regions. Thus, the prevalence of RP estimated in different studies fluctuates between $4 \%-20 \% .^{6-20}$ Among women the frequency of RP varies between $4 \%^{9141618}$ and $15 \%-20 \% .^{67111217}$ There is also a variety of the prevalence of RP in men ${ }^{6} 13^{14}{ }^{16-18}$ although it is found in lower frequency among men compared with women. Several studies have shown that climate, ${ }^{17} 2021$ occupation, ${ }^{1422}$ hormonal factors, ${ }^{23} 24$ migraine, ${ }^{25}{ }^{26}$ smoking, ${ }^{18}$ alcohol consumption ${ }^{27}$ and positive family history ${ }^{16}$ may correlate with $\mathrm{RP}$, while fish oil consumption improves 
primary $R P^{28}$ The key previous epidemiological studies of RP are shown in table 1 .

The aim of our study was to estimate the prevalence of RP in a healthy working Greek population and to investigate the possible association of RP with various demographic, social, occupational, dietary factors as well as with medical history and drug exposure. So far there were no such reports in our country. The study was conducted in Ioannina, a city with mild climate (mean January temperature $6.5^{\circ} \mathrm{C}$, mean July temperature $24.8^{\circ} \mathrm{C}$ ).

\section{Methods}

STUDY POPULATION

The survey was cross sectional and carried out between November 1997 and March 1998 in the University Hospital of Ioannina. The study population consisted of the administrative, technical and nursing personnel of the hospital aged above 18 years. A sample of 756 of 1392 working subjects was included in the survey. All the administrative employees (120 subjects) were invited to participate to the survey while representative samples of the technical (218 of 436 subjects) and nursing (418 of 836 subjects) personnel were included. The samples were randomly selected using tables of random numbers from the lists of the employees. Five hundred subjects responded to the invitation to participate, 111 men and 389 women. All of them were interviewed by one of two trained physicians who completed a specially conformed questionnaire for each subject. During this face to face interview a set of hand photographs showing typical attacks of $\mathrm{RP}$ was demonstrated to the subjects (phase I). All the employees who answered positively to the questions were recruited again and underwent a clinical examination (phase II). During the second phase of the survey, the diagnosis of $\mathrm{RP}$ was confirmed on the basis of a short interview and the method of immersion of the hands into an ice bath. All subjects with RP underwent an immunological evaluation. The following tests were performed: rheumatoid factor (RF) using latex, antinuclear antibodies
(ANA) using indirect immunofluorescence, cardiolipin antibodies (aCL) using ELISA and cryoglobulins. Thus, $20 \mathrm{ml}$ of non-heparinised peripheral venous blood were obtained in a warm syringe from all the subjects with RP. The blood samples were kept at $37^{\circ} \mathrm{C}$ until they clotted. Serum was separated by centrifugation at $37^{\circ} \mathrm{C}$ and then $10 \mathrm{ml}$ stored at $4^{\circ} \mathrm{C}$ for the detection of cryoglobulins, as previously reported, ${ }^{29}$ while the remaining was used for determination of RF, ANA and aCL.

QUESTIONNAIRE OF RP

The questionnaire used in the survey had previously been validated in a group of 40 patients with either primary or secondary RP (patients with scleroderma and systemic lupus erythematosus) visiting the outpatient Rheumatology Clinic of the University Hospital of Ioannina. In addition, 30 subjects known to have no symptoms of RP took part in this pilot study. Sensitivity of the questionnaire was estimated $97.5 \%$ and specificity $96.7 \%$.

At the beginning of the interview the subjects gave indentity information: name, address, phone number, sex, age and answered questions about their marital status, education and occupation. The questionnaire consisted of the following yes/no items:

(1) have you ever noticed your fingers changing colour, (a) in cold months (yes/no), (b) in cold water (yes/no), (c) in emotional stress (yes/no)?

(2) If yes (in any of the above a, b, c) they become (i) white (yes/no), (ii) blue (yes/no), (iii) red (yes/no), (iv) other?

(3) The colour change of your fingers is accompanied by: (a) numbness, (b) tingling, (c) paresthesias, (d) other sensory changes, (e) nothing (yes/no)?

(4) The colour change is noticed in both hands (yes/no)?

(5) How many years do your fingers change colour on cold exposure? (a) less than a year? (b) 1 to 5 years? (c) more than 5 years?

(6) Have you ever consulted your general practitioner or a specialist concerning these symptoms (yes/no)?

Table 1 Epidemiological studies of Raynaud's phenomenon

\begin{tabular}{|c|c|c|c|c|c|c|}
\hline & Authors & Geographical location & Number of subjects & Methods used & $\begin{array}{l}R P \text { in men } \\
(\%)\end{array}$ & $\begin{array}{l}R P \text { in women } \\
(\%)\end{array}$ \\
\hline 1990 & Weinrich MC & S Carolina & 5246 & interview - colour photos & 2.7 & 4.3 \\
\hline 1990 & Silman A & London & 1532 & $\begin{array}{l}\text { postal questionnaire } \\
\text { questionnaire when attending GP }\end{array}$ & $\begin{array}{l}11 \\
16\end{array}$ & $\begin{array}{l}19 \\
21\end{array}$ \\
\hline 1991 & Harada $\mathrm{N}$ & Japan & 3873 & $\begin{array}{l}\text { interview, photos } \\
\text { (excluding vibration trauma) }\end{array}$ & $\begin{array}{l}3.3 \\
1\end{array}$ & $\begin{array}{l}2.5 \\
1.8\end{array}$ \\
\hline 1992 & O’Keeffe ST & Burlington, USA & 750 (hospital employees) & questionnaire, interview, photos & 4 & 9 \\
\hline 1992 & Bartelink ML & Nijmegen, Netherlands & 508 & $\begin{array}{l}\text { validated questionnaire } \\
\text { RP monophasic white }\end{array}$ & $\begin{array}{r}0.5 \\
5.4\end{array}$ & $\begin{array}{r}2.9 \\
7.5\end{array}$ \\
\hline & & & & RP monophasic & 10.4 & 21.2 \\
\hline 1993 & Riera G & Girona, Spain & 1467 & questionnaire, interview, examination & 3.2 & 4.7 \\
\hline 1993 & Maricq HR & $\begin{array}{l}\text { Charleston, S. Carolina } \\
\text { Tarentaise Savoie France }\end{array}$ & 4086 & $\begin{array}{l}\text { telephone interview (phase I) } \\
\text { interview - examination (phase II) }\end{array}$ & $\begin{array}{r}4.3 \\
13.5\end{array}$ & $\begin{array}{r}5.7 \\
20.1\end{array}$ \\
\hline 1997 & Maricq HR & $\begin{array}{l}S \text { Carolina } \\
4 \text { regions in France }\end{array}$ & $\begin{array}{r}10149 \text { (phase I) } \\
1534 \text { (phase II) }\end{array}$ & $\begin{array}{l}\text { telephone survey } \\
\text { face to face interview } \\
\text { clinical evaluation }\end{array}$ & & \\
\hline & & -Charleston & & & 0.8 & 3.4 \\
\hline & & -Toulon & & & 2.8 & 11.4 \\
\hline & & -Nyons & & & 6.2 & 5.8 \\
\hline & & -Grenoble & & & 6.4 & 12.1 \\
\hline & & -Tarentaise & & & 6.3 & 15.8 \\
\hline 1997 & Valter I & $\begin{array}{l}\text { Tartu, Tartumaa, } \\
\text { S Estonia }\end{array}$ & $\begin{array}{l}2626 \text { (phase I) } \\
457 \text { (phase II) }\end{array}$ & $\begin{array}{l}\text { postal questionnaire } \\
\text { interview color charts }\end{array}$ & 7.9 & 8.3 \\
\hline
\end{tabular}

$\mathrm{RP}=$ Raynaud's phenomenon. 
Table 2 Prevalence of Raynaud's phenomenon according to age

\begin{tabular}{|c|c|c|c|c|c|c|c|c|c|c|}
\hline \multirow[b]{2}{*}{ Age groups } & \multicolumn{2}{|c|}{ 20-29 years } & \multicolumn{2}{|c|}{ 30-39 years } & \multicolumn{2}{|c|}{$40-49$ years } & \multicolumn{2}{|c|}{ 50-59 years } & \multicolumn{2}{|c|}{ All age groups } \\
\hline & $n$ & $\%(95 \% C I)$ & $n$ & $\%(95 \% C I)$ & $n$ & $\%(95 \% C I)$ & $n$ & $\%(95 \% C I)$ & $n$ & $\%(95 \% C I)$ \\
\hline $\begin{array}{l}\text { Men } \\
\text { CI }\end{array}$ & $0 / 20$ & 0 & $1 / 64$ & $\begin{array}{l}1.6 \\
(0,13)\end{array}$ & $0 / 25$ & 0 & $0 / 2$ & 0 & $1 / 111$ & $\begin{array}{l}0.9 \\
(0,8)\end{array}$ \\
\hline $\begin{array}{l}\text { Women } \\
\text { CI }\end{array}$ & $5 / 109$ & $\begin{array}{l}4.6 \\
(2,11)\end{array}$ & $17 / 204$ & $\begin{array}{l}8.3 \\
(4,13)\end{array}$ & $3 / 70$ & $\begin{array}{l}4.3 \\
(1,12)\end{array}$ & $0 / 6$ & 0 & $25 / 389$ & $\begin{array}{l}6.4 \\
(3,8)\end{array}$ \\
\hline $\begin{array}{l}\text { Total } \\
\text { CI }\end{array}$ & $5 / 129$ & $\begin{array}{l}3.9 \\
(2,10)\end{array}$ & $18 / 268$ & $\begin{array}{l}6.7 \\
(3,12)\end{array}$ & $3 / 95$ & $\begin{array}{l}3.2 \\
(1,10)\end{array}$ & $0 / 8$ & 0 & $26 / 500$ & $\begin{array}{l}5.2 \\
(3,7)\end{array}$ \\
\hline
\end{tabular}

The questionnaire also included questions about smoking (how many cigarettes per day, for how many years), alcohol consumption (glasses per week of wine, beer or other drink), caffeine use- because of its potential vasoconstrictive properties-(coffees per day), use of vibrating tools, medical history (migraine, haematological disorders, use of crutches, atherosclerosis, Prinzmetal), drug exposure ( $\beta$ blockers, oral contraceptives, vasoconstrictive agents) and dietary habits (consumption of olive oil and fishes).

DEFINITION OF RP

In this study, RP was defined as episodes of biphasic or triphasic colour changes of fingers on cold exposure or/and emotional stress, according to the UK Scleroderma Study Group. ${ }^{3}$

STATISTICAL ANALYSIS

Comparison between people presenting RP and all other persons was done using the $\chi^{2}$ test for categorical variables and $t$ test for continuous variables.

\section{Results}

DEMOGRAPHIC CHARACTERISTICS OF THE STUDY POPULATION AND PREVALENCE OF RP

A total of 500 (111 men and 389 women) of 756 people were interviewed (response rate $66.1 \%$ ). The overall mean (SD) age of the participants was 33.7 (6.2) years. RP was detected in 26 subjects ( 1 man and 25 women) with mean age 32.7 (5.8) years. More specifically, 33 subjects responded positively to the first question of our questionnaire, 26 subjects answered positively to the second one for at least two colours, while the remaining seven answered positively for one colour change (six for red colour and one for blue). For the third question, 27 subjects responded positively and finally, for the fourth question 28 subjects. However, only 26 fulfilled the Scleroderma Study Group criteria for RP. The remaining 474 employees ( 110 men and 364 women) had no RP and their mean age was 33.7 (6.2) years. The overall prevalence of RP was $5.2 \%$ and estimation by sex showed that the prevalence of $\mathrm{RP}$ was $0.9 \%$ in men and $6.4 \%$ in women (table 2). The sex ratio men/women was $1 / 7.1$. The prevalence of RP according to age showed that RP focuses on the fourth decade of life (table 2).

DESCRIPTION OF RP

Table 3 shows the conditions of appearance and duration of RP.
Finger whitening was described by 23 subjects $(88.5 \%)$ while cyanosis was found in 10 subjects $(38.5 \%)$ and blushing of fingers was present in 23 employees $(88.5 \%)$. RP consisted of biphasic colour changes in 22 subjects or $84.6 \%$ and of triphasic colour changes in four subjects or $15.4 \%$. Finger blanching was mainly noticed while cyanosis was less apparent. Sensory changes including numbness, tingling, pain, paresthesias that accompanied the episodes of RP were described by 19 subjects or $73.1 \%$.

CORRELATIONS OF RP

An association between RP and migraine was found (table 4 ). There were no statistically significant differences concerning marital status, education, occupation and the use of vibrating tools between subjects with and without RP (table 4). We also found no statistically significant difference with regard to smoking, alcohol consumption, intake of coffee, dietary habits (consumption of olive oil and fishes) between employees with RP and subjects without RP. Finally, there were no significant differences concerning the remaining medical history and drug exposure between subjects with and without RP.

CLINICAL AND IMMUNOLOGICAL EVALUATION Physical examination of the 26 subjects was unremarkable. RP was confirmed in all people by the method of immersion of the hands into an ice bath. Four of them presented positive ANA at low titres. No other immunological abnormalities were found. All subjects were found to have primary RP.

\section{Discussion}

$\mathrm{RP}$ is characterised by cutaneous colour changes on cold exposure. Diagnosis of RP is not always easy because there are healthy people who complain of not well defined episodic attacks of RP and no one laboratory assessment of RP is yet accepted as the gold standard. Thus, RP is difficult to diagnose in community

Table 3 Conditions of appearance and duration of Raynaud's phenomenon

\begin{tabular}{lll}
\hline & \multicolumn{3}{c}{ Subjects with Raynaud's phenomenon } \\
\cline { 2 - 3 } & $n=26 \%(95 \% C I)$ \\
\hline Conditions of appearance (yes/no) \\
cold weather & $22 / 4$ & $84.6 / 15.4(65,96) /(4,35)$ \\
cold water & $24 / 2$ & $92.3 / 7.7(71,98) /(2,29)$ \\
emotional stress & $7 / 19$ & $26.9 / 73.1(12,43) /(57,88)$ \\
Duration of Raynaud's phenomenon & \\
1-5 years & 4 & $15.4(4,35)$ \\
$>5$ years & 21 & $80.8(58,93)$ \\
unknown & 1 & $3.8(1,23)$ \\
\hline
\end{tabular}


Table 4 Association of Raynaud's phenomenon (RP) with marital status, education, occupational factors and migraine

\begin{tabular}{|c|c|c|c|c|c|}
\hline & \multicolumn{2}{|c|}{ Subjects with $R P$} & \multicolumn{2}{|c|}{ Subjects without $R P$} & \multirow[b]{2}{*}{$p$} \\
\hline & $n=26$ & $\%(95 \% C I)$ & $n=473$ & $\%(95 \% C I)$ & \\
\hline Marital status (married) & 19 & $73.1(54,91)$ & 358 & $75.5(69,81)$ & NS \\
\hline \multicolumn{6}{|l|}{ Education } \\
\hline$<6$ years & 3 & $11.5(2,30)$ & 58 & $12.2(7,15)$ & NS \\
\hline $6-12$ years & 14 & $53.8(34,75)$ & 245 & $51.7(45,56)$ & NS \\
\hline$>12$ years & 9 & $34.6(21,62)$ & 171 & $36.1(30,41)$ & NS \\
\hline \multicolumn{6}{|l|}{ Occupation } \\
\hline administrative personnel & 2 & $7.7(1,27)$ & 85 & $17.9(15,24)$ & NS \\
\hline nursing personnel & 17 & $65.4(43,83)$ & 250 & $52.7(46,58)$ & NS \\
\hline technical personnel & 7 & $26.9(10,48)$ & 138 & $29.1(25,35)$ & NS \\
\hline Use of vibrating tools & 3 & $11.5(2,30)$ & 124 & $26.2(21,31)$ & NS \\
\hline Medical history migraine & 12 & $46.2(25,66)$ & 94 & $19.8(16,25)$ & $<0.01$ \\
\hline
\end{tabular}

NS $=$ with no statistical significance

surveys. Nevertheless, the prevalence of RP has been estimated in several studies, varying between $4 \%-20 \%{ }^{6-20}$ Our study, the first conducted in north west Greece, is a cross sectional study carried out in the cold months of the year in a healthy working population.

It showed that the prevalence of RP in the closed healthy working population is $5.2 \%$. Comparisons of the estimations of RP prevelance among various studies are difficult because there are differences concerning the definition of RP, the methods of assessment, the characteristics of the sample and the occupational exposure. However, data from previous reports show that the prevalence of RP correlates well with differences in climate, higher values being observed in colder regions. ${ }^{17} 2021$ The low prevalence of RP found in various studies in Japan, ${ }^{13}{ }^{14}$ South Carolina, ${ }^{9}$ Spain ${ }^{16}$ and Southern Estonia ${ }^{18}$ including ours, suggest that geographical differences may be responsible. The hypothesis described by Maricq and colleagues ${ }^{20}$ that there is an aetiological relation between a cold climate and RP (that is, living in a cold climate helps produce in some people the susceptibility to have RP episodes on cold exposure) may explain the frequency differences of RP. The climate in the area of Ioannina, in north west Greece where the study was carried out, is mild and therefore the low prevalence of RP is not surprising. In addition to environmental (that is, climate), genetic factors may also influence the occurrence of RP and explain, at least partially, the geographical variation of RP.

In this study the prevalence of RP is higher $(6.4 \%)$ among women than men $(0.9 \%)$, which is in concordance with most reports. ${ }^{679} 12-1730$ There is also a variation of the RP frequency in several populations of women and men. Thus, among women the prevalence of RP fluctuates from $4 \%$ or less, in Japan, ${ }^{14}$ South Carolina, ${ }^{9}$ Spain $^{16}$ and Southern Estonia ${ }^{18}$ to $15 \%-20 \%$, in Sweden, ${ }^{11}$ Denmark, ${ }^{12}$ England $^{67}$ and Savoie, a mountainous region of France. ${ }^{17}$ The same picture is observed for men and the RP prevalence varies from very low $(1.2 \%)^{913141618}$ to more than $10 \% .^{6717}$ The higher prevalence of RP in women suggests that hormonal factors may play an important part in the pathophysiology of $\mathrm{RP},{ }^{23}$ although differing results have been published ${ }^{24}$ Fraenkel et al assumed that the role of oestrogen in RP might be explained by the potentiation of $\alpha$ adrenergic mediated vasoconstriction ${ }^{23} 31$ or by oestrogen effects, or both, on rheological factors. ${ }^{32} 33$

In our study, RP focuses on the fourth decade of life, while the age of onset of RP is found in the third decade. There was no statistically significant difference concerning age between subjects with and without RP. The age of onset of RP in our study is higher as compared with previous survey. ${ }^{20}$ This finding is consisted with the warmer climate of Ioannina.

In this investigation subjects with positive questionnaires were diagnosed having primary RP because: (1) RP affected both hands on cold exposure, (2) past medical history of the subjects was unremarkable, (3) clinical examination of the employees showed normal findings, (4) RP duration was more than five years in the majority of the subjects (21 of 26) without any additional complaints, (5) the immunological evaluation showed unremarkable results; we found no aCL in contrast with a recent publication. ${ }^{34}$

However, capillaroscopic examination was not performed in our study population. It is accepted that normal capillaries favour idiopathic or primary RP. ${ }^{16}{ }^{35}$ Very few of the subjects with RP had sought medical consultation, which is in agreement with other published results. ${ }^{6}$

We found no correlation of RP with marital status in contrast with a previous study. ${ }^{27} \mathrm{RP}$ was not correlated to the educational level of the subjects, which is in agreement with other reports. ${ }^{20}{ }^{27}$ It is known that occupational exposures to cold (for example, among workers in poultry slaughterhouses and canning factories $^{22}$ or to vibration ${ }^{14}$ ) are associated with RP. Working conditions among the studied subjects had no effect on the prevalence of RP. The majority of the employees reported only relatively short-term exposures to a variety of vibrating tools that do not have a well established record of RP induction. Similar mechanisms have been suspected for RP and migraine and several surveys as well as this study, have presented an association between the two diseases. ${ }^{111623252630}$

The potential role of tobacco smoking, which is known to have an effect on the peripheral circulation, ${ }^{37}$ has been investigated in several studies. ${ }^{12} 1618{ }^{36}$ Most of them, including ours, found no correlation of RP with smoking ${ }^{12} 161836$ although published data suggested an association between smoking ${ }^{11}$ or the quantity smoked ${ }^{12}$ and finger sensitivity to cold but not with RP.

We found no relation between RP and alcohol use. So far, only one study reported an increasing risk of RP with the quantity of alcohol consumed..$^{27}$ Dietary habits (consumption of olive oil and fishes), which are common in our country, have no influence on the prevalence of RP; more investigation is necessary as there are no similar correlations in the published surveys.

However, there are some limitations in our study that deserve consideration. Firstly, the cross sectional design precludes the ability to 
make causal inferences about the results. Secondly, our study population was comparatively small and 250 subjects who were included in the survey did not answer the questionnaire because of their absence for various reasons during the study. It is impossible to say if the number of missing subjects is related to an overestimation or underestimation of RP prevalence. Thirdly, only one man was diagnosed as having RP; this result sets some limitations upon drawing reliable conclusions with regard to men and RP. Finally, our study estimates the RP prevalence in a healthy working population and information drawn may not be generalisable to the general population. Nevertheless, our study is unique in Greece.

In conclusion, we estimated that the prevalence of RP (5.2\%) in a healthy Greek population is comparatively low, compared with previous studies. Environmental (climate) or genetic factors, or both, may contribute to this finding. RP affects mainly women and focuses on the fourth decade of life. Our results should be confirmed with other epidemiological studies of RP in the general population of Greece.

The secretarial assistance of Mrs Eleni Horti is gratefully acknowledged.

1 Klippel JH, Dieppe PA. Rheumatology. London: Mosby 1994:6.8.1-3.

2 Klippel JH, Weyand CM, Wortmann RL. Primer on the rheumatic diseases. 11 th ed. Atlanta, GA: Arthritis Foundation 1997:268.

3 Brennan P, Silman A, Black C, Bernstein R, Coppock J, Maddison $\mathrm{P}$, et al. Validity and reliability of three methods used in the diagnosis of Raynaud's phenomenon. The UK Scleroderma Study Group. Br J Rheumatol 1993;32:35761.

4 Skopouli FN, Talal A, Galanopoulou V, Tsampoulas CG, Drosos AA, Moutsopoulos HM. Raynaud's phenomenon in primary Sjögren's syndrome. J Rheumatol 1990;17:618in p

5 Wigley FM, Flavahan NA. Raynaud's phenomenon. Rheum Dis Clin North Am 1996;22:765-81.

6 Silman A, Holligan S, Brennan P, Maddison P. Prevalence of symptoms of Raynaud's phenomenon in general practice. BMJ 1990;22:590-2.

7 Heslop J, Coggon D, Acheson ED. The prevalence of intermittent digital ischaemia (Raynaud's phenomenon) in a general practice. J Roy Coll Gen Pract 1983;33:85-9.

8 Maricq HR, Weinrich MC, Keil JE, Le Roy EC. Prevalence of Raynaud's phenomenon in the general population. A preliminary study by questionnaire. J Chron Dis 1986;39: 423-7.

9 Weinrich MC, Maricq HR, Keil JE, McGregor AR, Diat F. Prevalence of Raynaud phenomenon in the adult population of South Carolina. J Clin Epidemiol 1990;43:1343-9.

10 Walker DD, Jones B, Ogston S, Tasker EG, Robinson AJ. A study of white finger in the gas industry. BMJ 1985;42: 672-7.

11 Leppert J, Aberg H, Ringqvist I, Sörensson S. Raynaud phenomenon in a female population: prevalence and associanomenon in a female population: prevalence and asso

12 Olsen N, Nielsen SL. Prevalence of primary Raynaud's phenomenon in young females. Scand J Clin Lab Invest 1978 37:761-4.

13 Iwata H, Makimo S, Miyashita K. Prevalence of Raynaud's phenomenon in individuals not using vibrating tools. Sangyo Igaku 1987;20:500-3

14 Harada N, Ueda A, Takegata S. Prevalence of Raynaud's phenomenon in Japanese males and females. J Clin Epidemiol 1991;44:649-55.

15 Bartelink ML, Wollersheim M, Van de Lisdonk E, Spruijt R, Van Weel C. Prevalence of Raynaud's phenomenon. Neth J Med 1992;41:149-52.
16 Riera G, Vilardell M, Vaqué J, Fonollosa V, Bermejo B. Prevalence of Raynaud's phenomenon in a healthy Spanish population. J Rheumatol 1993;20:66-9.

17 Maricq HR, Carpentier PH, Weinrich MC, Keil JE, Franco $\mathrm{A}$, Drouet $\mathrm{P}$, et al. Geographic variation in the prevalence of Raynaud's phenomenon: Charleston, SC, USA, vs Tarentaise, Savoie, France. J Rheumatol 1993;20:70-6.

18 Valter I, Maricq HR. Prevalence of Raynaud phenomenon in Tartu and Tartumaa, southern Estonia. Scand J Rheumatol 1997;26:117-24.

19 O'Keefee ST, Tsapatsaris NP, Beetham WP Jr. Color chart assisted diagnosis of Raynaud's phenomenon in an unselected hospital employee population. J Rheumatol 1992;19:1415-17.

20 Maricq HR, Carpentier PH, Weinrich MC, Keil JE, Palesch $\mathrm{Y}$, Biro C, et al. Geographic variation in the prevalence of Raynaud's phenomenon: A 5 region Comparison. J Rheumatol 1997;24:879-89.

21 Yu ZS, Chao H, Qiao L, Qian DS, Ye YH. Epidemiologic survey of vibration syndrome among riveters, chippers and grinders in the rail road system of the People's Republic of China. Scand J Work Environ Health 1986;12:289-92.

22 Kaminski M, Bourgine M, Zins M, Touranchet A, Verger C. Risk factors of Raynaud's phenomenon among workers in poultry slaughterhouses and canning factories. Int J Epidemiol 1997;26:371-80.

23 Fraenkel L, Zhang Y, Chaisson CE, Evans SP, Wilson PWF, Felson DT. The association of estrogen replacement therapy and the Raynaud phenomenon in postmenopausal women. Ann Intern Med 1998;129:208-11.

24 Bartelink ML, Wollersheim H, Van de Lisdonk E, Thien T. Raynaud's phenomenon: subjective influence of female sex hormones. Int Angiol 1992;11:309-15.

25 Bartelink ML, van de Lisdonk E, van den Hoogen $\mathrm{H}$, Woller Sheim $\mathrm{H}$, van Weel C. Migraine in family practice: prevalence and influence of sex hormonal status. Fam Med 1993;25:331-6.

26 O'Keefee ST, Tsapatsaris NP, Beetham WP Jr. Association between Raynaud's phenomenon and migraine in a random population of hospital employees. J Rheumatol 1993;20:1187-8.

27 Keil JE, Maricq HR, Weinrich MC, McGregor AR, Diat F. Demographic, social and clinical correlates of Raynaund phenomenon. Int J Epidemiol 1991;19:221-4.

28 Di Giacomo RA, Kremer JM, Shah DM. Fish oil supplementation in patients with Raynaud's phenomenon: A double-blind controlled prospective study. Am J Med $1989 ; 86: 158$

29 Tzioufas AG, Manoussakis MN, Costello R, Silis M, Papadopoulos NM, Moutsopoulos HM. Cryoglobulinemia in autoimmune rheumatic diseases. Evidence of circulating monoclonal cryoglobulins in patients with primary Sjögren's syndrome. Arthritis Rheum 1986;29:1098-104.

30 De Trafford JC, Lafferty K, Potter CE, Roberts VC, Cotton LT. An epidemiological survey of Raynaud's phenomenon. Eur J Vasc Surg 1988;2:167-70

31 Coffman JD, Cohen RA. Alpha-2 adrenergic and 5-HT 2 receptor hypersensitivity in Raynaud's phenomenon. J Vasc Med Biol 1990;2:100-6.

32 Solerte SB, Fioravanti M, Spinillo A, Ferrari E, Guaschino S. Association between hormonal and haemorheological changes during the menstrual cycle in healthy women. $\mathrm{Br} \mathrm{J}$ Obstet Gynaecol 1988;95:1305-8.

33 Levine JD, Taiwo YO. Beta-estradiol induced catecholamine-sensitive hyperalgesia: a contribution to pain in Raynaud's phenomenon. Brain Res 1989;487: $143-7$.

34 Vayssairat M, Abuaf N, Baudot N, Deschamps A, Gaitz JP. Abnormal IgG cardiolipin antibody titers in patients with Raynaud's phenomenon and/or related disorders: prevalence and clinical significance. J Am Acad Dermatol 1998; 38:555-8.

35 Harper FE, Maricq HR, Turner RE, Lidman RW, Leroy EC. A prospective study of Raynaud phenomenon and early connective tissue disease. A five-year report. Am J Med 1982;72:883-8.

36 Houtman PM, Kallemberg CG, Fidler V, Wouda AA. Diagnostic significance of nailfold capillary patterns in patients with Raynaud's phenomenon. J Rheumatol 1986;13:55663.

37 Gemne G. Pathophysiology and multifactorial etiology of acquired vasospastic disease (Raynaud syndrome) in vibration-exposed workers. Scand J Work Environ Health $1982 ; 8: 243-9$. 